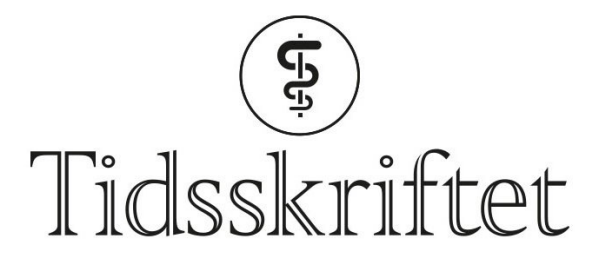

DEN NORSKE LEGEFORENING

\title{
Fortidens epidemier og karantener
}

I TIDLIGERE TIDER

\section{PER HOLCK}

E-post: per.holck@medisin.uio.no

Per Holck er dr.med. og professor emeritus i anatomi ved Institutt for medisinske basalfag ved Universitetet i Oslo.

Forfatteren har fylt ut ICMJE-skjemaet og oppgir ingen interessekonflikter.

Selv i vårt Europa, med et teknifisert og velutstyrt helsevesen, har det under covid-19pandemien til tider oppstått en følelse av hjelpeløshet og frykt for sykdom som er uvant for nåtidens mennesker. Kanskje kan det være interessant med et historisk tilbakeblikk til fortidens epidemier?

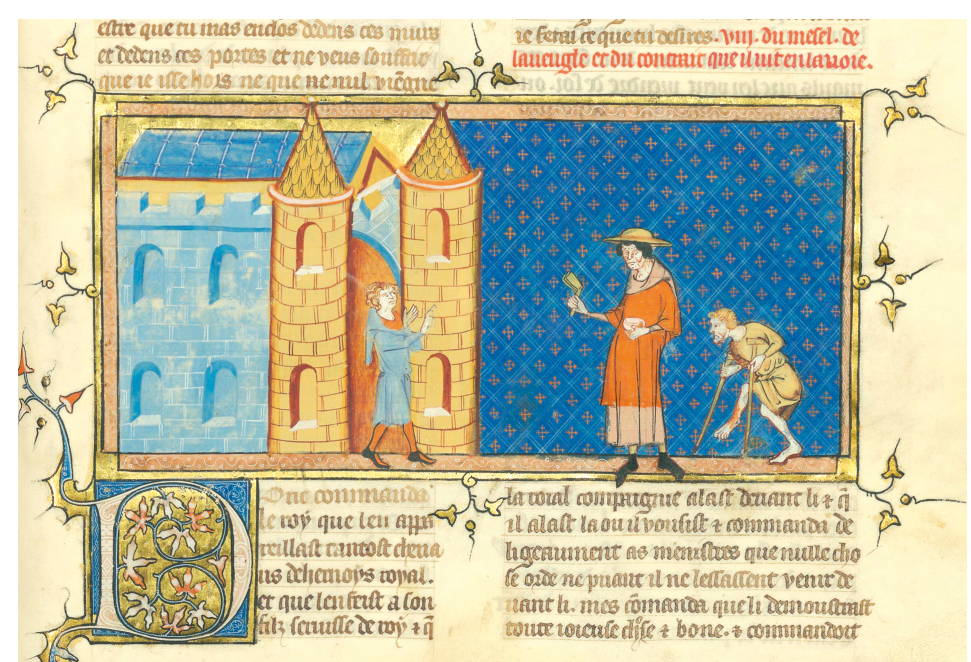

Leprasyke avvises ved byporten. Miniatyr fra Speculum historiale av Vincent de Beauvais, midten av 130o-tallet. Illustrasjon: Bibliothèque nationale de France

Koronaviruspandemien har flere paralleller i fortiden, hvor menneskene har hatt den samme angsten for sykdom og død, og kanskje stilt de samme spørsmålene som vi gjør nå. Hvordan kan man begrense smitte? Hvorfor blir noen mer syke enn andre, eller ikke syke i det hele tatt? Hvorfor angripes ikke barn på lik linje med voksne? Noe helbredende middel hadde man ikke under fortidens epidemier - og det har vi heller ikke nå.

I middelalderen fulgte forståelsen og behandlingen av sykdom stort sett den antikke medisinens tradisjon, hvor oldtidskapasitetene Aristoteles og Galenos og deres behandlingsmetoder ble holdt i hevd. Men i det avsidesliggende Norge holdt man i langt større grad fast ved gammel, nedarvet sykdomsoppfatning basert på magi. Her mente man at det var overnaturlige makter som sto bak sykdom, og slikt kunne være farlig å motarbeide. Det er ingen tegn til at gresk antikk medisin var kjent eller brukt (1, s. 96). I stedet hadde man en fatalistisk innstilling, også langt inn i kristen tid. Sykdom var Herrens 
straff, og både profylakse og terapi besto i religiøse handlinger for å mildne Guds vrede.

\section{Karantener}

Angsten for det ukjente og letingen etter løsninger som vi har sett den siste tiden under pandemien, har flere likhetstrekk med fortidens primitive medisin. Karantenen har røtter tilbake til 130o-tallets «sunnhetskommisjoner» i Venezia, og ble siden et mønster for flere andre land. Ved å holde skip med mannskap og varer som kom langveisfra, i isolasjon en viss tid, kunne man hindre at de spredte smittsomme sykdommer som de eventuelt brakte med seg. I 1383 ble skipenes liggetid satt til «omtrent 40» - quarantaine - dager i Marseille (2, s. 106). Inkubasjonstiden er sjelden lengre for infeksjonssykdommer, men de 40 dagene har nok mer vært et slags «magisk» tidsrom, og neppe valgt av medisinske årsaker alene. Moses tilbrakte jo 40 dager på Sinaifjellet, syndflodens regn varte i 40 dager og netter, Jesus oppholdt seg 40 dager i ørkenen. Og i eldre tid ble barselkvinnene i Norge ansett som «urene» i 40 dager etter fødselen, og ble nærmest holdt i karantene før de igjen fikk delta i gudstjenesten. Vår hjemlige karantenelov ble ikke satt ut i livet før i 1848.

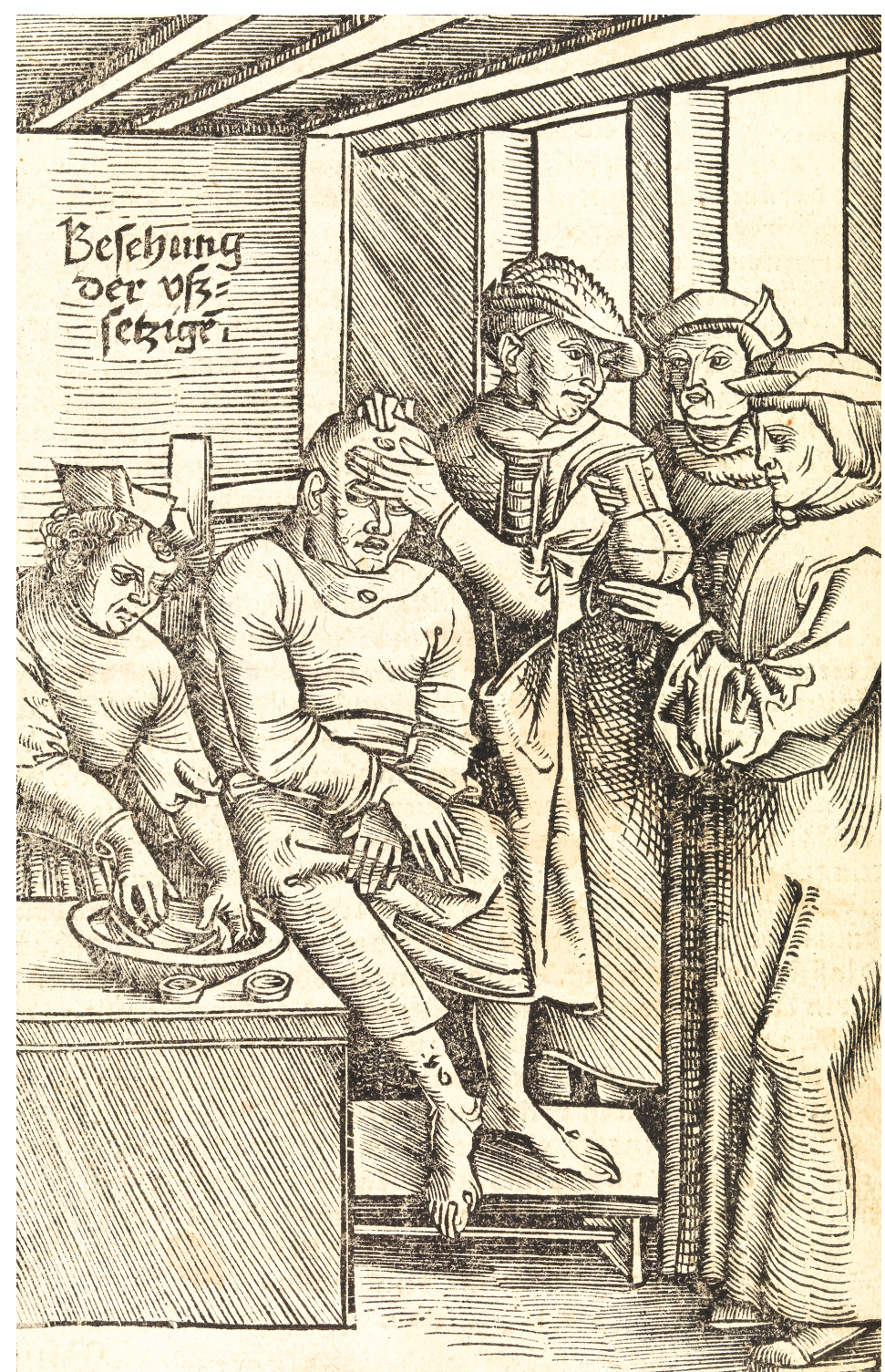

Undersøkelse av en spedalsk. Tresnitt i Feldtbuch der Wundarzney av Hans von Gersdorff, 1517. Illustrasjon: Wellcome collection

\section{Epidemier}

Vi har ikke mye litteratur i vår del av verden hvor epidemier og sykdomsforståelse i tidligere tider er beskrevet. Men i Øyrbyggja saga, hvor det fortelles om hendelser fra tiden da kristendommen ble innført på Island, altså rundt år 10oo, hører vi om noe som antagelig er 
en beskrivelse av en flekktyfusepidemi (3), men som fremstilles som en overnaturlig hendelse.

Sagaen beretter om en kvinne, Torgunna, som kom til gården Frodå på nordøstsiden av sagaøya (4). Hun kom med et skip fra Dublin og hadde med seg kostbarheter som ingen hadde sett maken til. Kona til bonden på gården ville gjerne kjøpe noe av det, men fikk bryskt beskjed om at det var ikke til salgs. Etter en tid ble Torgunna syk, og nå skjedde det underlige ting: Det regnet blod ned på henne fra en sky. Torgunna gikk hjem til sengekammeret sitt og tok av seg de blodige klærne. Hun skjønte at hun snart kom til å dø, og sa at det ville komme flere dødsfall etter hennes. Hun påla bonden å brenne sengen og alle sengeklærne hennes, og det lovet han. Men kona innsmigret seg hos ham og fikk beholde de fineste delene.

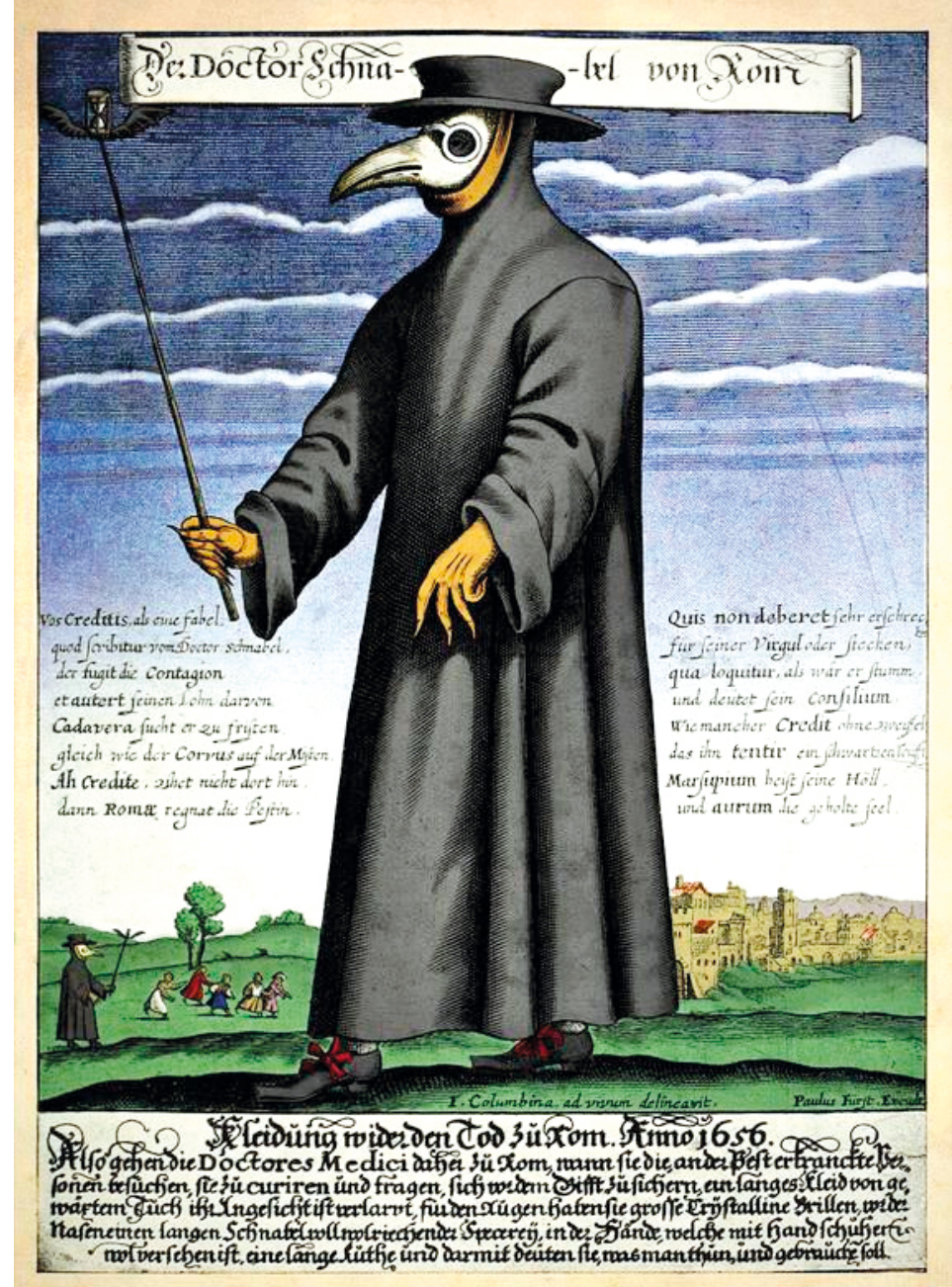

Pestlege i Roma. Drakten er innsatt med voks. Han har briller og hansker og beskytter munn og nese med et nebb fylt med velluktende urter. Stikk av Paul Furst, 1656. Kolorisert på et senere tidspunkt. Illustrasjon: Wikimedia commons

Vi kan få inntrykk av at utlendingen Torgunna forsto hva «smitte» var, noe Frodå-bonden åpenbart ikke hadde innsikt i. Torgunna dør, men går igjen som et spøkelse og tar snart den ene, snart den andre med seg. Det blir ikke bedre før presten kommer til stedet. Alt sengetøyet blir brent og huset renset med vievann. Da er 18 av gårdens folk døde (4, s. 94).

Flekktyfus (typhus exanthematicus) overføres ved bitt av lus og kan dukke opp under dårlige hygieniske forhold (5, s. 445). Den er karakteristisk ved at kapillarene skades og gir blødninger, både i huden og i indre organer. Bedret hygiene med vask - både med og uten vievann - reduserer utbredelsen.

\section{Spedalskhet}

Sykdommen spedalskhet, også betegnet som lepra, har til alle tider blitt fryktet, til tross for 
at smittsomheten er liten. Ja, den har figurert i Guinness rekordbok som verdens minst smittsomme sykdom (6, s. 22).

Middelalderens mennesker så nok annerledes på det, og i Norge, hvor den fatalistiske holdningen fortsatt rådet, mente man at det å bli spedalsk nærmest var skjebnebestemt. Man ble syk fordi man var fattig. Lenge mente man også at spedalskhet var arvelig (7, s. 39). Derfor holdt sykdommen seg lenger her enn i de fleste andre land i Europa.

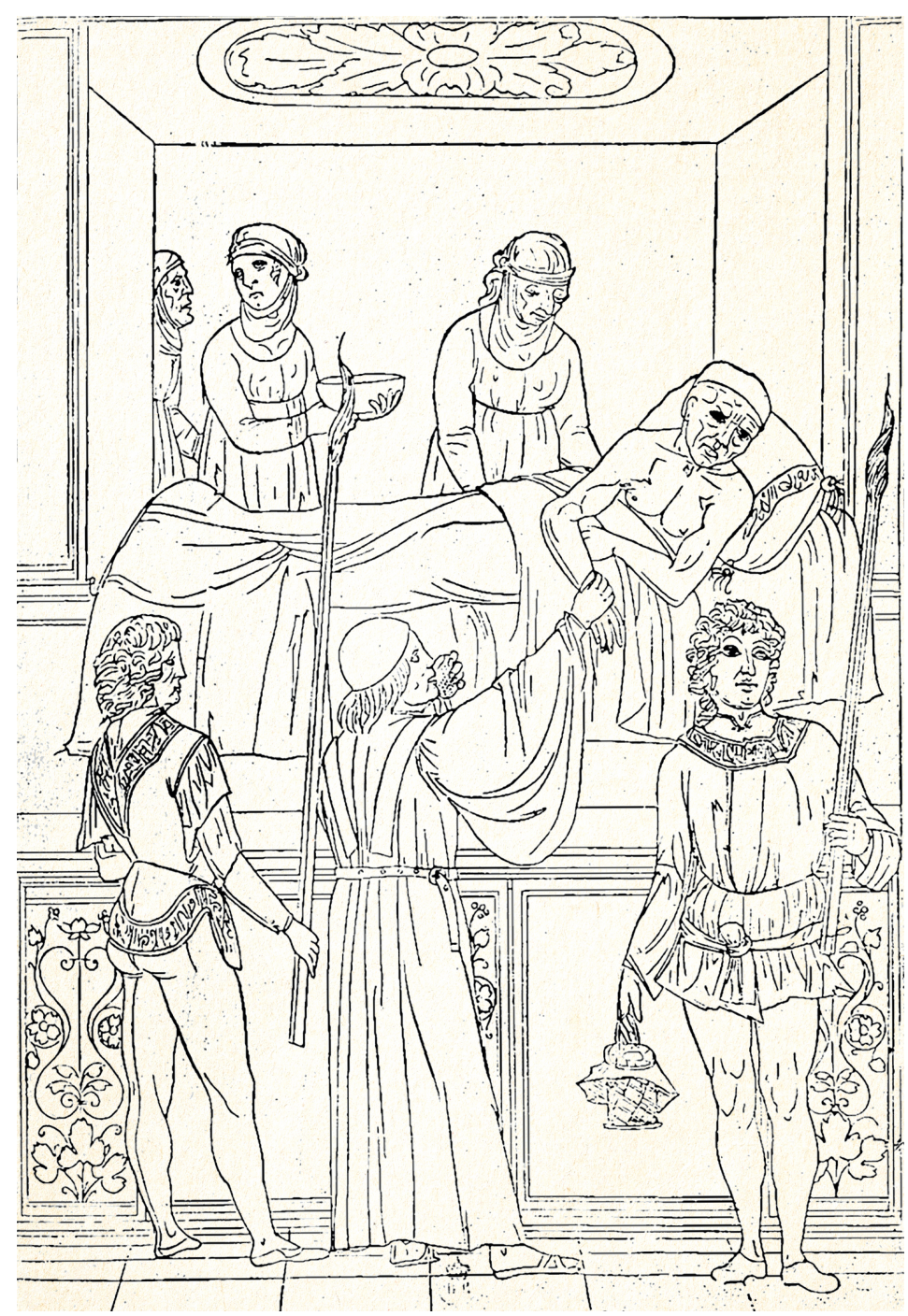

Lege på besøk hos en pestsyk. Legen holder en svamp som beskyttelse foran nese og munn. Assistenten bcerer en fakkel for å «rense» luften. Tegning av Gentile Bellini, ca. 149o. Illustrasjon: Wellcome collection

På kontinentet hadde man andre holdninger. Å bli spedalsk var det samme som å bli utstøtt av samfunnet, derfor var det viktig at diagnosen var korrekt. Men hvem var best kvalifisert til å stille slike diagnoser? Jo, det var de spedalske selv! Ved det store leprahospitalet Melaten i Köln, hvor det var strenge bestemmelser, hadde man et «ekspertteam» av både menn og kvinner (8, s. 74-8o). Undersøkelsen av den som var mistenkt for å ha sykdommen, måtte foregå i fullt dagslys, og pasienten måtte være helt avkledd. Den som foretok undersøkelsen, måtte ikke motta gaver, dvs. bestikkelser, og «dommen» - diagnosen - ble meddelt den syke under ed.

En slik diagnose fikk store konsekvenser for den det gjaldt. Han måtte leve avsondret fra både familien og samfunnet for øvrig, og ble behandlet som avdød. Mange steder var det forbudt for den syke å gjøre innkjøp eller i det hele tatt å ha kontakt med omverdenens friske mennesker, både i kirken, i vertshuset og på markedet. Den syke måtte ikke vaske hendene i rennende vann. Ville han kjøpe noe, var det bare tillatt å peke på varen, og ville han snakke med noen, måtte det skje mot vinden. Passerte han en bro, måtte han ikke berøre rekkverket annet enn med hansker på. Og fremfor alt: Han måtte ikke komme i 
kontakt med barn!

Siden de fattige ikke behøvde å betale for undersøkelsen og oppholdet, ble de syke sendt ut for å tigge penger og mat for å opprettholde hospitalets økonomi, men da i følge med en ansatt som sørget for å holde avstand til andre, og som med en bjelle eller rangle forkynte den sykes ankomst.

\section{Pestepidemiene}

Det har oppstått pestepidemier i Europa flere ganger, fra folkevandringstiden og opp mot 170o-tallet - den siste i Norge i 1654 (1, s. 305). Best kjent er nok epidemien svartedauden i årene 1347-51. Også her skilte Norge seg ut fra det øvrige Europa ved selvoppgivende holdninger. Den svensk-norske kongen, Magnus Eriksson (1316-74), befalte at det skulle holdes messe for å be jomfru Maria om å gå i forbønn for menneskene hos Gud (1, s. 97). Noen fors $ø$ på behandling ble ellers ikke iverksatt, for man skulle jo ikke gå imot Guds vilje, hvis det nå var slik at Han hadde sendt pesten som straff for menneskenes synder. Derfor var det heller ingen forbud mot å drive handel eller dra på pilegrimsferd. Man ga seg Herren i vold og forsøkte å leve som før.

På kontinentet mente legene at man i stedet burde isolere seg, eller flykte fra pesten, slik vi kjenner det fra Boccaccios Il Decamerone (1353). Årsakene mente man lå i forgiftet luft miasma - som ofte, men ikke alltid skyldtes planetenes konstellasjon (7, s. 58). Likevel var det vanskelig å forklare hvorfor bare noen ble syke når menneskene tross alt pustet inn den samme luften. For sikkerhets skyld prøvde man å «rense» den med brennende bål og fakler på gater og torg. En svamp holdt man for nese og munn som beskyttelse.

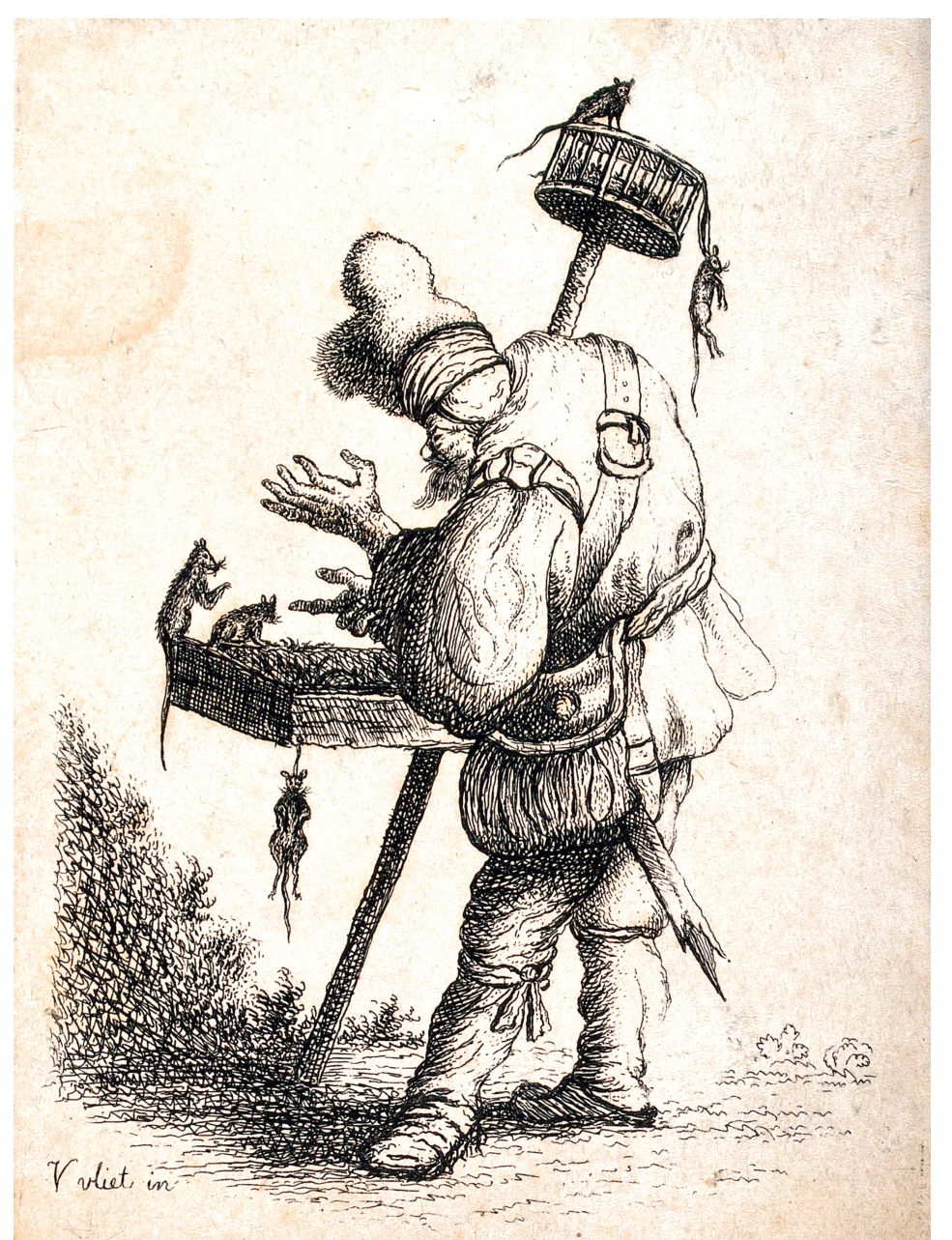

Rottefangere var viktige personer i middelalderens bysamfunn. Radering av Jan Georg van Vliet, 1622. Illustrasjon: Wellcome collection

Først på 1500-tallet syntes dette synet å ha endret seg, og man begynte å forstå at pesten faktisk kunne overføres ved direkte kontakt mellom mennesker, og ikke bare var en 
himmelsk straffedom. Man skjønte at det kunne være farlig å bruke klær etter dem som var døde av pest, ja, at selv øvrighetspersoner kunne være pestkilder, og at den dødelige sykdommen kanskje kunne bekjempes ved aktiv innsats og bruk av medisin samt isolasjon (7, s. 6o).

Mange andre epidemier kan nevnes - både kolera, kopper, syfilis og tuberkulose, som alle har hatt det til felles at menneskene i begynnelsen sto hjelpeløse og var uten tilstrekkelig kunnskap om sykdommens vesen (9). Først etter 1870-årene, med oppdagelsen av bakteriene, begynte en ny æra i menneskenes forståelse av smitte.

\section{LITTERATUR:}

1. Benedictow OJ. Svartedauen og senere pestepidemier i Norge. Oslo: Unipub forlag, 2002.

2. Villner K. Blod, kryddor och sot. Läkekonst för 350 år sedan. Stockholm: Carlsson Bokförlag, 1986.

3. Holck P. Flekktyfus på sagatidens Island? Tidsskr Nor Legeforen 2011; 131: 2504-6.

[PubMed][CrossRef]

4. Øyrbyggja saga, oversatt av SA.Wiik, Norrøn saga, bd. 3. Oslo: Aschehoug, 1990.

5. Natvig, H. Lærebok i hygiene. Oslo: Liv og Helses forlag, 1970.

6. Guinness rekordbok. Først og størst, sist og minst. 2. utg. Oslo: Chr. Schibsteds forlag, 1968.

7. Tuft G. Epidemier før AIDS. Oslo: JW. Cappelens forlag, 1989.

8. Irsigler F, Lassotta F. Bettler und Gaukler, Dirnen und Henker. Aussenseiter in einer mittelalterlichen Stadt. Köln: Greven Verlag, 1984.

9. Holck P. Koleraåret 1833. St.Hallvard 1977; 55:130-6.

Publisert: 29. juni 2020. Tidsskr Nor Legeforen. DOI: 10.4045/tidsskr.20.0387

(C) Tidsskrift for Den norske legeforening 2020. Lastet ned fra tidsskriftet.no 